SVN Vascular
Neurology

\title{
CCM3 and cerebral cavernous malformation disease
}

\author{
Kang Wang, Huanjiao Jenny Zhou, Min Wang
}

To cite: Wang K, Zhou HJ, Wang M. CCM3 and cerebral cavernous malformation disease. Stroke and Vascular Neurology 2019;4: e000195. doi:10.1136/svn-2018-000195

Received 19 0ctober 2018 Revised 22 January 2019 Accepted 12 February 2019 Published Online First 2 March 2019
Check for updates

(C) Author(s) (or their employer(s)) 2019. Re-use permitted under CC BY-NC. No commercial re-use. See rights and permissions. Published by BMJ.

Interdepartmental Program in Vascular Biology and Therapeutics, Department of Pathology, Yale University School of Medicine, New Haven, Connecticut, USA

Correspondence to Dr Min Wang, Interdepartmental Program in Vascular Biology and Therapeutics, Department of Pathology Yale University School of Medicine New Haven Connecticut USA;

wang.min@yale.edu

\section{ABSTRACT}

Cerebral cavernous malformations (CCMs) are vascular lesions characterised by enlarged and irregular structure of small blood vessels in the brain, which can result in increased risk of stroke, focal neurological defects and seizures. Three different genes, CCM1/Krev/Rap1 Interacting Trapped 1, CCM2/MGC4607 and CCM3/ PDCD10, are associated with the CCMs' progression, and mutations in one of three CCM genes cause CCM disease. These three CCM proteins have similar function in maintaining the normal structure of small blood vessels. However, CCM3 mutation results in a more severe form of the disease which may suggest that CCM3 has unique biological function in the vasculature. The current review focuses on the signalling pathways mediated by CCM3 in regulating endothelial cell junction, proliferation, migration and permeability. These findings may offer potential therapeutic strategies for the treatment of CCMs.

\section{INTRODUCTION}

Cerebral vascular malformations affect $0.1 \%-4 \%$ of the general population and fall into four categories: arteriovenous malformations, venous malformations, capillary telangiectases and cerebral cavernous malformations (CCMs). CCMs consist of clusters of enlarged endothelial channels ('caverns') that are arranged back-to-back to form densely packed sinusoids with little or no intervening brain parenchyma. $^{1-5}$ These lesions lack smooth muscle/pericyte and elastic tissue, and lack sub-endothelial support and an intact basal lamina, so the vessel walls are thin and prone to leakage. Ultra-structural analysis has revealed decreased numbers of pericytes, endothelial detachment from the basal lamina and ruptures in the luminal endothelium probably due to reduced/damaged intercellular junctions. ${ }^{6}$ CCMs are primarily found within the neurovasculature of the central nervous system (CNS, ie, brain, spinal cord, retina), where they result in increased risk for stroke, seizures and focal neurological deficits. ${ }^{3-5}$ Currently, the only treatment for CCM is surgical resection. CCMs may be familial or sporadic. Familial cases are caused by mutations in one of three CCM genes: CCM1 (also known as Krev/Rap1 Interacting Trapped 1KRIT1), ${ }^{7}$ CCM2 (also known as malcavernin or osmosensing scaffold for mitogen-activated protein kinase kinase-3-osm) ${ }^{8}$ and CCM3 (also known as programmed cell death 10-PDCD10). ${ }^{9}$ These three CCM proteins can be found in the same complex within the cell and recent studies suggest that all CCM proteins regulate EndMT (endothelial-to-mesenchymal transition), which contributes to the onset and progression of CCM. ${ }^{10-15}$ However, CCM3 might also act separately from CCM1 and CCM2, as its mutation in humans often results in a more severe form of the disease, ${ }^{16} 17$ and CCM3 knockout mice show severe phenotypes with yet-to-be defined mechanisms. ${ }^{10-14}$

Bergametti et al first identified PDCD10 as the third CCM gene, which is located on 3q25.2-27. ${ }^{9}$ After the relationship between PDCD10 and CCMs was elucidated, a variety of biological functions of this protein related to CCMs have been reported. This review focuses on the role of CCM3 in regulating cell junction, maintaining normal structure and function of vascular endothelial cells, and angiogenesis, which all can be involved in the progression of CCMs.

\section{CCM3 AND THE CEREBROVASCULAR DISEASE}

The role of CCM3 in cell junction

The normal cell junction of endothelial cells is important to maintain the normal structure and function of blood vessels, which are often disrupted in CCM lesions. Cell-cell junctions especially tight junctions are essential to prevent blood-borne compounds from leaking to brain parenchyma, which further leads to inflammatory responses, endothelial injury and lesion progression. ${ }^{18}$ Stamatovic et $a l^{20}$ have found that CCM3 regulates brain endothelial barrier integrity and tight junction complex organisation. Loss of CCM3 activates extracellular signal-regulated kinase (ERK1/2); activated ERK1/2 induces Ser phosphorylation (pS405) of cortactin (a cortical actin ring protein), which leads to cortactin degradation. Increased cortactin degradation is associated with loss of the cortical actin ring and ZO-1: actin interactions, which are essential for providing 
physical support and anchoring of tight junction proteins. The reduced anchoring of ZO-1 to the actin cytoskeleton impacts organisation of tight junction proteins, and eventually disrupts the tight junction complex.

CCM3 also may affect tight junction by indirectly interaction with CCM1, as CCM1 has been proved to maintain Rap-1 mediated stabilisation of endothelial junction and VE-Cadherin mediated adherens junctions. ${ }^{21}{ }^{22}$ CCM3 and germinal-centre kinase III (GCKIII) family associated with striatin also interact with the CDC42 binding kinase myotonic dystrophy kinase-related CDC42-binding kinase, which promotes circumferential actin bundles essential for junction formation. ${ }^{23}$

\section{The role of CCM3 in angiogenesis}

Angiogenesis is a process that involves endothelial cells proliferation, migration and morphology remodelling. He $e t a l^{24}$ have shown that CCM3 knockdown in human umbilical vein endothelial cells significantly reduces endothelial cell proliferation and induced cell apoptosis, and also inhibits vascular endothelial growth factor (VEGF-induced endothelial cell) cord formation. CCM3 specifically associates with VEGFR2 and was required for stabilisation of VEGFR2, thereby maintaining the VEGF signalling pathway which is essential for angiogenesis.

CCM3 can be involved in different signalling pathways as an anchor protein which can bind to different target proteins. The best-characterised interaction between CCM3 and its target proteins lies in the dimerisation-domain-mediated interaction with the GCKIII group of kinases, MST4/MASK, STK24/MST3 and STK25/YSK1/ SOK $1 .{ }^{25}$

Zhang et $a l^{26}$ have first proved that CCM3 associates with STK24 and regulates exocytosis in neutrophils. STK24 binds to UNC13D C2B domain and prevent UNC13D from binding to lipids, a step important for vesicle docking. CCM3 can stabilise the STK24 protein, and there is a degranulation phenotype in neutrophils during loss of either CCM3 or STK24. Then Jenny Zhou et $a l^{27}$ has subsequently uncovered that CCM3 regulates exocytosis in endothelial cells. CCM3 can inhibit UNC13-mediated intracellular molecules exocytosis by combining with UNC13B and STK24. Thus, loss of CCM3 increases ANGPT-2 release from Weibel-Palade bodies in brain endothelial cells. Increased ANGPT-2 secretion to the extracellular space disrupts the association between endothelial cells and pericytes, leading to enhanced endothelial cell spouting, and lumen formation followed by CCM lesion formation.

Zheng $e t a l^{28}$ that loss of CCM3 or STK24 also results in actin stress fibre formation and elevated RhoA activation in endothelial cells, so ANGPT-2 induced excessive sprouting and lumen formation along with weakened cell adhesion and increased permeability result in an abnormal and disrupted blood vessel.

Zhou et $a l^{29}$ have reported that CCM complex associated with GCKIII kinases regulates MEKK3 pathway in endocardial cells. Endocardial deletion of CCM1/CCM2/
CCM3 activates MEKK3 and the downstream MEK4 and ERK5. Activated ERK5 could be transported into the nuclei and upregulate the transcription factor KLF2/4 and proteases a disintegrin and metalloproteinase with thrombospondin motifs (ADAMTS4/5). Zhou et $a l^{29}$ also demonstrate that MEKK3-KLF2/4 signalling is critical for the CCM progression.

\section{Other mechanisms about CCM3 regulates CCM progression}

EndMT is characterised by the acquisition of mesenchymal and stem-cell-like features of endothelium. ${ }^{30} 31$ The progression of EndMT leads to disrupted cell junction organisation, loss of cell polarity, increased cell proliferation and migration. ${ }^{32}$ Maddaluno et $a l^{13}$ have shown that EndMT exists in $C C M 1^{\mathrm{ECKO}}$ and $C C M 3^{\mathrm{ECKO}}$ mice with disorganised VE-Cadherin and significantly up-regulated N-Cadherin, and this progress is mediated by the upregulation of endogenous BMP6, which in turn activates the TGF- $\beta$ (transforming growth factor- $\beta$ ) and BMP (bone morphogenetic protein) signalling pathway. Inhibiting TGF- $\beta$ or BMP pathway prevents EndMT and reduces CCM lesion in mice. Autophagy is also related to CCM formation and EndMT. ${ }^{33}$

Louvi $e t a l^{34}$ have found that CCM3 deletion in neural cells results in a vascular phenotype that resemble human CCMs, which suggests CCM3 may affect CCM progression through cell death pathway. Fidalgo $e t a l^{35}$ have also found that CCM3-GCKIII kinase (MST4) mediates ezrin/ radixin/moesin phosphorylation and cell survival after reactive oxygen species (ROS) stimulating. Interestingly, ROS can be induced by CCM3 deletion in endothelial cells. ${ }^{33}$ All of these studies suggest ROS may be a factor implicated in loss of CCM3-dependent CCMs progression.

CCM3 may play an important role in other biological phenomenon besides CCM lesion. Guerrero $e t a p^{36}$ have reported that lack of CCM3 impairs the senescence response of cells, which is related to the inability of CCM3-deficient cells to induce the C/EBP $\beta$ transcription factor. CCM3-deficient cells also have a defect in autophagy which may suggest an evidence of immortal cells, and one study reveals a relationship between CCM3 mutation and high risk of tumour. ${ }^{37}$

\section{Progression in CCM therapy}

The only treatment for CCM disease is surgical resection so far, although there is high risk for cerebral operation. To date, no medical therapy has been approved. Based on the researches of molecular mechanism which regulate CCM progression, some drugs which affect intracellular signalling pathway can be effective in animal trials. Administration of fasudil, a Rho-kinase inhibitor, results in attenuated CCM lesion in mice with CCM1 mutations. ${ }^{33}$ Statin inhibits HMG-CoA reductase, which reduces RhoA-dependent small GTPase activation, and presents a symptomatic improvement in mouse model ${ }^{38}$ but administration of statin is associated with increased risk of intracerebral haemorrhage,${ }^{39}$ and hence more researches should be done before the application of statin in CCM therapy. 


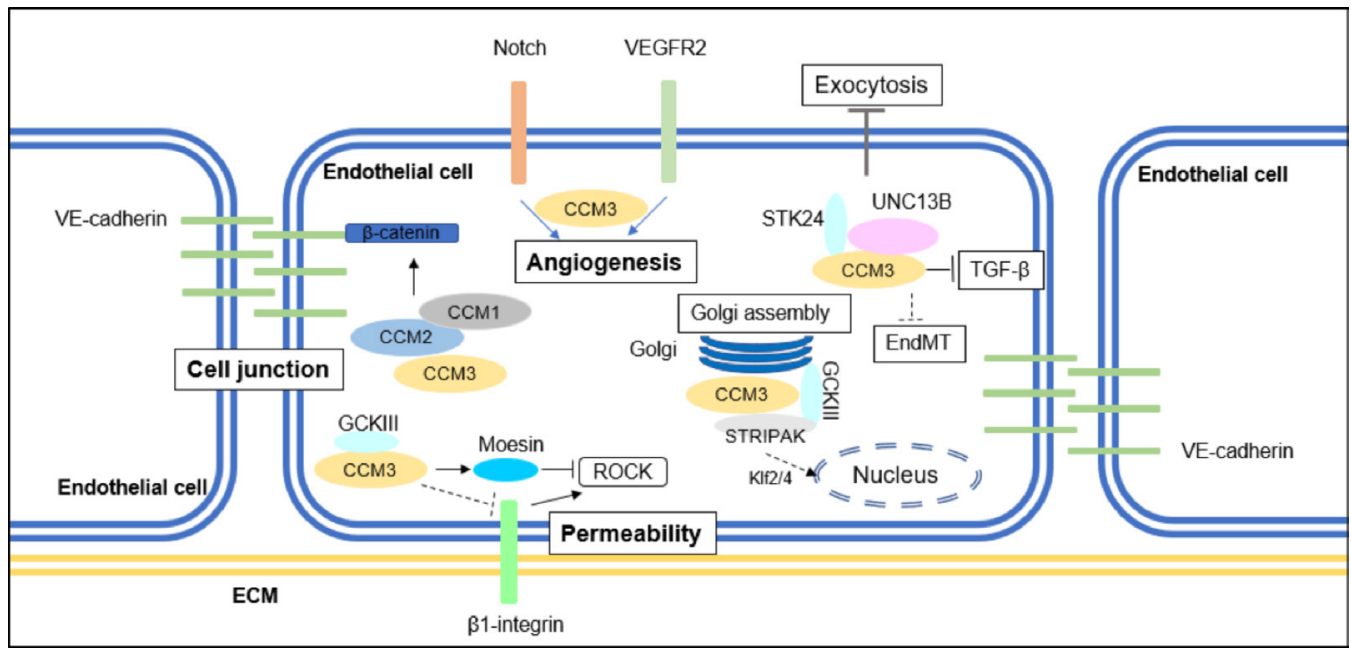

Figure 1 A summary of CCM3-mediated signalling pathways implicated in CCM formation. CCM3 maintains cell junction by inhibiting ERK1/2 phosphorylation; CCM3 inhibits stress fibre migration and endothelial permeability by inhibiting RhoA signalling; CCM3 regulates angiogenesis with or without binding to GCKIII kinases. CCM3 also mediates EndMT transition, autophagy and ROS stimulation. CCM, cerebral cavernous malformation; EndMT, endothelial-to-mesenchymal transition; GCKIII, germinal-centre kinase III; VE, vascular endothelial.

ANGPT2-neutralising antibody significantly reduces CCM lesion formation in $C C M 3^{\mathrm{ECKO}}$ mice. ${ }^{27}$ TLR4 (Tolllike receptor 4) antagonists and alteration of microbiome can affect CCM formation in mice. ${ }^{40}$ Many advances have been made, but further studies are still needed to uncover novel mechanisms regulating CCMs and develop effective drugs preventing the progression of CCMs.

\section{CONCLUSION}

As an anchor protein, CCM3 binds to different type of proteins; this enables CCM3 take part in different intracellular signalling which affect cell junction, angiogenesis, apoptosis and stress responses (figure 1). Some controversial results may exist related to specific CCM3-mediated pathways observed in isolated endothelial cells. The current prevailing view is that the primary defects in CCM are endothelial cells-intrinsic in humans, and this has been confirmed by endothelial cell-specific gene deletion in mouse models. We have to consider that CCM lesion is a comprehensive result of all different pathways in the neurovascular unit, which consists of several cell types, including endothelial cells, pericytes, astrocytes and neuronal cells. Despite the mounting knowledge about the role of CCM3 in the progression of CCMs, several fundamental questions need to be addressed in the CCM field. Why are CCM lesions primarily confined to brain vasculature despite CCM proteins are ubiquitously expressed in all tissues? The unique feature of the brain vasculature is the blood brain barrier (BBB) formed by the brain neurovascular unit. It is unknown whether or not the unique BBB structure and the interactions of endothelial cells with neural cells and pericytes play a critical role in CCM lesion development. We don't know the effect of CCM3 on translational and post-translational modifications of those tight junction proteins, and how CCM3 regulates $\beta 1$ integrin signalling. Recent study uncovered a relationship between innate immune/microbiome and CCM lesion in mice with CCM1/2 deficiency. Whether or not CCM3 is linked to the innate immune pathway is unclear yet. We should notice that there may be other CCM-related genes, as mutations in CCM1/CCM2/ CCM3 do not cover all the familiar cases. There is no doubt that further studies are necessary to better understand the mechanism and pathogenesis of CCMs and find a non-invasive therapy for CCM disease.

Correction notice This article has been corrected since it was published. Dr. Min Wang's name was incorrectly transposed.

Contributors KW wrote the article, HJZ and WM provided guidance and modifications.

Funding This work was supported by National Key Research and Development Program of China (2016YFC1300600), National Natural Science Foundation of China (No. U161219), Science Grant of Guangzhou (2016040220131), and Science grants of Guangdong (No. 2015B020225002). This work was partly supported by NIH grants R01 HL136507, R01HL109420 and HL115148.

Competing interests None declared.

Patient consent for publication Not required.

Provenance and peer review Commissioned; externally peer reviewed. Data sharing statement No additional data are available.

Open access This is an open access article distributed in accordance with the Creative Commons Attribution Non Commercial (CC BY-NC 4.0) license, which permits others to distribute, remix, adapt, build upon this work non-commercially, and license their derivative works on different terms, provided the original work is properly cited, appropriate credit is given, any changes made indicated, and the use is non-commercial. See: http://creativecommons.org/licenses/by-nc/4.0/.

\section{REFERENCES}

1. Otten P, Pizzolato GP, Rilliet B, et al. [131 cases of cavernous angioma (cavernomas) of the CNS, discovered by retrospective analysis of 24,535 autopsies]. Neurochirurgie 1989;35:82-3.

2. Rigamonti D, Hadley MN, Drayer BP, et al. Cerebral cavernous malformations. Incidence and familial occurrence. $N$ Engl J Med 1988;319:343-7. 
3. Revencu N, Vikkula M. Cerebral cavernous malformation: new molecular and clinical insights. J Med Genet 2006;43:716-21.

4. Draheim KM, Fisher OS, Boggon TJ, et al. Cerebral cavernous malformation proteins at a glance. J Cell Sci 2014;127(Pt 4):701-7.

5. Cavalcanti DD, Kalani MY, Martirosyan NL, et al. Cerebral cavernous malformations: from genes to proteins to disease. J Neurosurg 2012;116:122-32.

6. Tanriover G, Sozen B, Seker A, et al. Ultrastructural analysis of vascular features in cerebral cavernous malformations. Clin Neurol Neurosurg 2013;115:438-44.

7. Sahoo T, Johnson EW, Thomas JW, et al. Mutations in the gene encoding KRIT1, a Krev-1/rap1a binding protein, cause cerebral cavernous malformations (CCM1). Hum Mol Genet 1999;8:2325-33.

8. Liquori CL, Berg MJ, Siegel AM, et al. Mutations in a gene encoding a novel protein containing a phosphotyrosine-binding domain cause type 2 cerebral cavernous malformations. Am J Hum Genet 2003;73:1459-64.

9. Bergametti F, Denier C, Labauge P, et al. Mutations within the programmed cell death 10 gene cause cerebral cavernous malformations. Am J Hum Genet 2005;76:42-51.

10. Chan AC, Drakos SG, Ruiz OE, et al. Mutations in 2 distinct genetic pathways result in cerebral cavernous malformations in mice. $J$ Clin Invest 2011;121:1871-81.

11. Cunningham $\mathrm{K}$, Uchida $\mathrm{Y}, \mathrm{O}^{\prime}$ Donnell $\mathrm{E}$, et al. Conditional deletion of $\mathrm{Ccm} 2$ causes hemorrhage in the adult brain: a mouse model of human cerebral cavernous malformations. Hum Mol Genet 2011;20:3198-206.

12. Boulday G, Blécon A, Petit N, et al. Tissue-specific conditional CCM2 knockout mice establish the essential role of endothelial CCM2 in angiogenesis: implications for human cerebral cavernous malformations. Dis Model Mech 2009;2:168-77.

13. Maddaluno L, Rudini N, Cuttano R, et al. EndMT contributes to the onset and progression of cerebral cavernous malformations. Nature 2013;498:492-6.

14. Shenkar R, Shi C, Rebeiz T, et al. Exceptional aggressiveness of cerebral cavernous malformation disease associated with PDCD10 mutations. Genet Med 2015;17:188-96.

15. Stahl S, Gaetzner S, Voss K, et al. Novel CCM1, CCM2, and CCM3 mutations in patients with cerebral cavernous malformations: inframe deletion in CCM2 prevents formation of a CCM1/CCM2/CCM3 protein complex. Hum Mutat 2008;29:709-17.

16. Denier C, Labauge P, Bergametti F, et al. Genotype-phenotype correlations in cerebral cavernous malformations patients. Ann Neurol 2006;60:550-6.

17. Zhu $Y$, Wu $Q$, Fass $M$, et al. In vitro characterization of the angiogenic phenotype and genotype of the endothelia derived from sporadic cerebral cavernous malformations. Neurosurgery 2011;69:722-32. discussion 31-2.

18. Shenkar R, Shi C, Check IJ, et al. Concepts and hypotheses: inflammatory hypothesis in the pathogenesis of cerebral cavernous malformations. Neurosurgery 2007;61:693-702. discussion -3.

19. Shenkar R, Venkatasubramanian PN, Wyrwicz AM, et al. Advanced magnetic resonance imaging of cerebral cavernous malformations: part II. Imaging of lesions in murine models. Neurosurgery 2008;63:790-7. discussion 7-8

20. Stamatovic SM, Sladojevic N, Keep RF, et al. PDCD10 (CCM3) regulates brain endothelial barrier integrity in cerebral cavernous malformation type 3: role of CCM3-ERK1/2-cortactin cross-talk. Acta Neuropathol 2015;130:731-50.
21. Glading A, Han J, Stockton RA, et al. KRIT-1/CCM1 is a Rap1 effector that regulates endothelial cell cell junctions. J Cell Biol 2007;179:247-54.

22. Glading AJ, Ginsberg MH. Rap1 and its effector KRIT1/CCM1 regulate beta-catenin signaling. Dis Model Mech 2010;3:73-83.

23. Lant B, Yu B, Goudreault M, et al. CCM-3/STRIPAK promotes seamless tube extension through endocytic recycling. Nat Commun 2015;6:6449.

24. He Y, Zhang H, Yu L, et al. Stabilization of VEGFR2 signaling by cerebral cavernous malformation 3 is critical for vascular development. Sci Signal 2010;3:ra26.

25. Sugden PH, McGuffin LJ, Clerk A. SOcK, MiSTs, MASK and STicKs: the GCKIII (germinal centre kinase III) kinases and their heterologous protein-protein interactions. Biochem J 2013;454:13-30.

26. Zhang $\mathrm{Y}$, Tang $\mathrm{W}$, Zhang $\mathrm{H}$, et al. A network of interactions enables CCM3 and STK24 to coordinate UNC13D-driven vesicle exocytosis in neutrophils. Dev Cell 2013;27:215-26.

27. Jenny Zhou H, Qin L, Zhang H, et al. Endothelial exocytosis of angiopoietin-2 resulting from CCM3 deficiency contributes to cerebral cavernous malformation. Nat Med 2016;22:1033-42.

28. Zheng $\mathrm{X}, \mathrm{Xu} \mathrm{C}$, Di Lorenzo $\mathrm{A}$, et al. CCM3 signaling through sterile 20-like kinases plays an essential role during zebrafish cardiovascular development and cerebral cavernous malformations. J Clin Invest 2010;120:2795-804.

29. Zhou Z, Tang AT, Wong WY, et al. Cerebral cavernous malformations arise from endothelial gain of MEKK3-KLF2/4 signalling. Nature 2016;532:122-6.

30. Medici D, Shore EM, Lounev VY, et al. Conversion of vascular endothelial cells into multipotent stem-like cells. Nat Med 2010;16:1400-6.

31. Zeisberg EM, Tarnavski O, Zeisberg M, et al. Endothelial-tomesenchymal transition contributes to cardiac fibrosis. Nat Med 2007;13:952-61.

32. Kalluri R, Weinberg RA. The basics of epithelial-mesenchymal transition. J Clin Invest 2009;119:1420-8.

33. Marchi S, Corricelli M, Trapani E, et al. Defective autophagy is a key feature of cerebral cavernous malformations. EMBO Mol Med 2015;7:1403-17.

34. Louvi A, Chen L, Two AM, et al. Loss of cerebral cavernous malformation $3(\mathrm{Ccm} 3)$ in neuroglia leads to $\mathrm{CCM}$ and vascular pathology. Proc Natl Acad Sci U S A 2011;108:3737-42.

35. Fidalgo M, Fraile M, Pires A, et al. CCM3/PDCD10 stabilizes GCKIII proteins to promote Golgi assembly and cell orientation. J Cell Sci 2010;123(Pt 8):1274-84.

36. Guerrero A, Iglesias C, Raguz S, et al. The cerebral cavernous malformation 3 gene is necessary for senescence induction. Aging Cell 2015;14:274-83.

37. Riant F, Bergametti F, Fournier HD, et al. CCM3 Mutations Are Associated with Early-Onset Cerebral Hemorrhage and Multiple Meningiomas. Mol Syndromol 2013;4:165-72.

38. Whitehead KJ, Chan AC, Navankasattusas S, et al. The cerebral cavernous malformation signaling pathway promotes vascular integrity via Rho GTPases. Nat Med 2009;15:177-84.

39. Westover MB, Bianchi MT, Eckman MH, et al. Statin use following intracerebral hemorrhage: a decision analysis. Arch Neurol 2011;68:573-9.

40. Tang AT, Choi JP, Kotzin JJ, et al. Endothelial TLR4 and the microbiome drive cerebral cavernous malformations. Nature 2017;545:305-10. 